\title{
Within-day repeatability for absolute quantification of Lawsonia intracellularis bacteria in feces from growing pigs
}

Pedersen, Ken Steen; Pedersen, Klaus H.; Hjulsager, Charlotte Kristiane; Larsen, Lars Erik; Ståhl, Marie ; Stege, Helle; Angen, Øystein; Nielsen, Jens Peter

Published in:

Journal of Veterinary Diagnostic Investigation

Link to article, DOI:

$10.1177 / 1040638712452111$

Publication date:

2012

Document Version

Publisher's PDF, also known as Version of record

Link back to DTU Orbit

Citation $(A P A)$ :

Pedersen, K. S., Pedersen, K. H., Hjulsager, C. K., Larsen, L. E., Ståhl, M., Stege, H., Angen, Ø., \& Nielsen, J. P. (2012). Within-day repeatability for absolute quantification of Lawsonia intracellularis bacteria in feces from growing pigs. Journal of Veterinary Diagnostic Investigation, 24(5), 968-970.

https://doi.org/10.1177/1040638712452111

\section{General rights}

Copyright and moral rights for the publications made accessible in the public portal are retained by the authors and/or other copyright owners and it is a condition of accessing publications that users recognise and abide by the legal requirements associated with these rights.

- Users may download and print one copy of any publication from the public portal for the purpose of private study or research.

- You may not further distribute the material or use it for any profit-making activity or commercial gain

- You may freely distribute the URL identifying the publication in the public portal 


\section{Journal of Veterinary Diagnostic Investigation \\ http://vdi.sagepub.com/}

Within-day repeatability for absolute quantification of Lawsonia intracellularis bacteria in feces from growing pigs

Ken Steen Pedersen, Klaus H. Pedersen, Charlotte Hjulsager, Lars Erik Larsen, Marie Ståhl, Helle Stege, Øystein Angen and Jens Peter Nielsen

J VET Diagn Invest 2012 24: 968 originally published online 11 July 2012

DOI: $10.1177 / 1040638712452111$

The online version of this article can be found at:

http://vdi.sagepub.com/content/24/5/968

\section{Published by: \\ (\$SAGE}

http://www.sagepublications.com

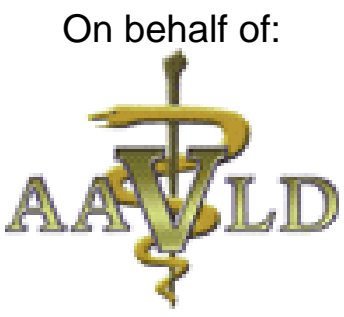

Official Publication of the American Association of Veterinary Laboratory Diagnosticians, Inc.

Additional services and information for Journal of Veterinary Diagnostic Investigation can be found at:

Email Alerts: http://vdi.sagepub.com/cgi/alerts

Subscriptions: http://vdi.sagepub.com/subscriptions

Reprints: http://www.sagepub.com/journalsReprints.nav

Permissions: http://www.sagepub.com/journalsPermissions.nav

>> Version of Record - Aug 22, 2012

OnlineFirst Version of Record - Jul 11, 2012

What is This? 


\author{
Ken Steen Pedersen, ${ }^{1}$ Klaus H. Pedersen, Charlotte Hjulsager, Lars Erik Larsen, \\ Marie Ståhl, Øystein Angen, Helle Stege, Jens Peter Nielsen
}

\begin{abstract}
Absolute quantification of Lawsonia intracellularis by real-time polymerase chain reaction (PCR) is now possible on a routine basis. Poor repeatability of quantification can result in disease status misclassification of individual pigs when a single fecal sample is obtained. The objective of the current study was to investigate overall variation within a day for fecal numbers of $L$. intracellularis bacteria determined by real-time PCR in growing pigs. From each of 30 pigs with an infection of L. intracellularis, 5 fecal samples were collected within 1 day. A total of 150 fecal samples were obtained and subjected to quantitative PCR (qPCR) testing. Mean fecal dry matter content was 14.3\% (standard deviation $=4.5 \%$ ). Two pigs $(6.7 \%)$ alternated between being $L$. intracellularis qPCR positive and negative. For 28 pigs, the excreting levels of $L$. intracellularis were within the dynamic range of the qPCR assay at all sampling points. For these 28 pigs, the mean excretion level of L. intracellularis was $6.1 \log _{10}$ bacteria/g feces (standard deviation $=1.2 \log _{10}$ bacteria/g feces). The maximum observed difference between 2 fecal samples from the same pig was $1.1 \log _{10}$ bacteria/g feces. The average standard deviation for individual pigs was $0.27 \log _{10}$ bacteria/g feces. The average coefficient of variation within pigs was 0.04 , ranging from 0.006 to 0.08 . The results imply that absolute quantification of $L$. intracellularis by qPCR has acceptable repeatability within 1 day. However, a population-specific proportion of pigs alternating between positive and negative test results must be expected.
\end{abstract}

Key words: Fecal samples; Lawsonia intracellularis; pigs; quantitative real-time polymerase chain reaction; within-day variation.

Lawsonia intracellularis is an obligate intracellular bacterium associated with intestinal disease in growing pigs. ${ }^{2}$ It is considered among the most economically important infections in the swine industry worldwide. ${ }^{1}$ Routine culture methods are not possible for L. intracellularis; therefore, testing of fecal samples by qualitative polymerase chain reaction (qPCR) has been applied for diagnosis of L. intracellularisassociated disease in diagnostic laboratories around the world. ${ }^{5}$ However, interpretation of these traditional qualitative fecal PCR tests is difficult in terms of importance for the individual pig. ${ }^{5}$ Real-time qPCR tests have been applied for absolute quantification of bacteria in clinical samples involving other agents, and a correlation between excretion level and disease severity has been demonstrated. ${ }^{4}$ Furthermore, clinically important levels for bacterial load have been established in other diseases. ${ }^{8}$ In 2009, qPCR tests were developed for absolute quantification of $L$. intracellularis in fecal samples. ${ }^{3}$ Absolute quantification of L. intracellularis by qPCR could potentially enhance interpretation of fecal PCR test results if numbers of $L$. intracellularis bacteria in feces and disease severity are correlated. Absolute quantification of L. intracellularis in routine diagnostics requires a high repeatability and reproducibility for quantification of clinical samples. A poor repeatability/reproducibility could potentially result in misclassification in relation to disease status when a single fecal sample is obtained from an individual. Repeatability/reproducibility for absolute quantification by qPCR can be influenced by features inherent to the qPCR assay (intra- and interassay variation) and biological variation (i.e., homogeneity of the fecal samples [intrasample variation] and variation in excretion level between fecal samples obtained from the same individual within the same day [within-day variation]). The objective of the current study was to investigate overall variation within a day for fecal absolute quantification of $L$. intracellularis by real-time PCR in growing pigs.

A cross-sectional study with follow-up was performed. No published reports of within-day variation of L. intracellularis in fecal samples were available for sample size calculations.

From HERD-Centre for Herd Oriented Education, Research and Development, Department of Large Animal Sciences, University of Copenhagen, Copenhagen, Denmark (KS Pedersen, KH Pedersen, Stege, Nielsen), and the National Veterinary Institute, Technical University of Denmark, Copenhagen, Denmark (Hjulsager, Larsen, Ståhl, Angen).

${ }^{1}$ Corresponding Author: Ken Steen Pedersen, Department of Large Animal Sciences, University of Copenhagen, Groennegaardsvej 2, DK1870 Frederiksberg C, Denmark. ken@life.ku.dk. 
A working sample size for the study was based on the practical aspects of collecting the fecal samples. One person should collect all fecal samples. It was considered possible to obtain fecal samples from approximately 30 pigs in $1-1.5 \mathrm{hr}$. A Danish farrow-to-finish herd with a history of $L$. intracellularis infection was selected by purpose sampling. The herd was selected based on a previous history of $L$. intracellularis. A total of 30 pigs were selected at convenience from a batch of 350 pigs that were approximately 8 weeks old having an outbreak of diarrhea. Based on previous laboratory herd examinations, the pigs were expected to be naturally infected by $L$. intracellularis. The selected pigs had not received antibiotic treatment within the last 4 weeks, and treatment of the current diarrhea outbreak was not initiated until after the fecal samples were collected. Selected pigs were identified by 2 identical ear tags. Fecal samples (10-50 g/sample) were collected 5 times during 1 day (at $9 \mathrm{AM}, 11 \mathrm{AM}, 1 \mathrm{PM}, 3 \mathrm{PM}$, and 5 PM) from the rectum of each pig using a new plastic glove for each pig. At each collection time, the pigs were handled in the same chronological order. All fecal samples were kept at $4^{\circ} \mathrm{C}$ and further processed the following day.

Fecal samples were mixed with a spoon and diluted to $10 \%$ in phosphate buffered saline (PBS). Total DNA was extracted using a commercial kit. ${ }^{a}$ One negative extraction sample of other bacterial cells and 1 positive extraction sample of $L$. intracellularis were included in each experiment. The amount of $L$. intracellularis in feces was determined with a qPCR termed the Laws-qPCR assay. ${ }^{7}$ For absolute quantification of $L$. intracellularis, a standard curve was made from $10 \%$ pig feces, negative by qPCR and spiked with a 10 -fold dilution of the reference strain $L$. intracellularis (strain 15540) as earlier described. ${ }^{7}$ Each qPCR experiment included the same reference concentrations of pure DNA in triplicate and facilitated adjustment of the standard curves to each new qPCR run. ${ }^{7}$ The dynamic range of the Laws-qPCR was $4 \times 10^{3}$ to $4 \times 10^{8}$ bacteria/g feces, and the limit of detection was $10^{2}$ bacteria/g feces. All fecal samples were subjected to fecal dry matter $(\mathrm{DM} \%)$ determination in a microwave oven as previously described. ${ }^{6}$

Prior to data analysis, qPCR results were $\log _{10}$ transformed to obtain a normal distribution. Initial descriptive analysis was performed using different summary statistics and plots. Overall variation for the individual pigs was evaluated by calculation of the standard deviation (SD) and coefficient of variation $(\mathrm{CV})$. Trends for SD in relation to increasing mean excretion levels in the individual pigs were investigated by linear regression. Commercial statistical software $^{\mathrm{b}}$ was used for all analyses.

A total of 150 fecal samples for qPCR testing were obtained. Mean fecal dry matter content was $14.3 \%$ ( $\mathrm{SD}=$ $4.5 \%)$. All pigs had a minimum of 1 qPCR-positive fecal sample. Two of the pigs were $L$. intracellularis qPCR negative in 1 and 3 of the fecal samples, respectively. One of these pigs alternated from below to above the limit of detection, while the other pig was below the limit of detection in 1 sample, within the dynamic range in 1 sample, and above the limit of detection but below the dynamic range in 3 samples.

The results from these 2 pigs could not be included in the statistical analyses of overall quantitative variation because of the missing values of $L$. intracellularis excretion level. A total of 28 pigs were excreting L. intracellularis at a level within the dynamic range of the Laws-qPCR assay at all time points. A total of 140 fecal samples obtained from these 28 pigs were included in the statistical analysis. The mean excretion level of L. intracellularis was $6.1 \log _{10}$ bacteria/g feces $\left(\mathrm{SD}=1.2 \log _{10}\right.$ bacteria/g feces). The maximum observed difference between 2 fecal samples from the same pig was $1.1 \log _{10}$ bacteria/g feces. The average SD for individual pigs was $0.27 \log _{10}$ bacteria/g feces. A linear association between $\mathrm{SD}$ and mean excretion level was not demonstrated $(P=0.37)$. The average $\mathrm{CV}$ within pigs was 0.04 , ranging from 0.006 to 0.08 .

For fecal qPCR quantification of L. intracellularis, 95\% of all samples from an average pig can be expected to be within approximately $1 \log _{10}$ bacteria/g feces. Furthermore, the probability of observing a value more than $0.5 \log _{10}$ bacteria from the true excretion level is below 0.025 . The results imply that absolute quantification of $L$. intracellularis by real-time PCR has a good repeatability within 1 day. Therefore, qPCR has the potential to be applied as a quantitative test for diagnosis of $L$. intracellularis-associated disease in individual pigs.

However, 2 pigs alternated from below to above the limit of detection in the current study. This illustrates that samples obtained at different time points can result in different classification of individuals in relation to infection and/or disease status. The 2 pigs were probably having a true excretion level close to the limit of detection. Therefore, the overall variation between samples within the same day would result in test results being above or below the limit of detection from one examination to the next. However, this problem is not specifically associated to absolute quantification by PCR tests. This problem of classification bias is relevant for any PCR test or culture method from fecal samples. The proportion of pigs alternating between positive and negative test results will depend on the fecal level of bacteria in the specific population of pigs.

Absolute quantification of $L$. intracellularis by real-time PCR has an acceptable repeatability within 1 day. However, a population-specific proportion of pigs alternating between positive and negative test results must be expected, resulting in false-negative disease classification.

\section{Sources and manufacturers}

a. QIAamp DNA Stool Mini Kit, Qiagen GmbH, Hilden, Germany.

b. Stata/IC version 11, StataCorp LP, College Station, TX. 


\section{Declaration of conflicting interests}

The author(s) declared no potential conflicts of interest with respect to the research, authorship, and/or publication of this article.

\section{Funding}

The author(s) disclosed receipt of the following financial support for the research, authorship, and/or publication of this article: This work was financially supported by Boehringer Ingelheim, Denmark.

\section{References}

1. Lawson GH, Gebhart CJ: 2000, Proliferative enteropathy. J Comp Pathol 122:77-100.

2. McOrist S, Gebhart CJ: 1999, Proliferative enteropathies. In: Diseases of swine, ed. Straw BE, Zimmerman JJ, D'Allaire S, and Taylor DJ, pp. 727-738. Blackwell, Ames, IA.

3. Nathues H, Holthaus K, Beilage E: 2009, Quantification of Lawsonia intracellularis in porcine faeces by real-time PCR. J Appl Microbiol 107:2009-2016.
4. Pahl A, Kühlbrandt U, Brune K, et al.: 1999, Quantitative detection of Borrelia burgdorferi by real-time PCR. J Clin Microbiol 37:1958-1963.

5. Pedersen KS, Holyoake P, Stege H, Nielsen JP: 2010, Diagnostic performance of different fecal Lawsonia intracellularis-specific polymerase chain reaction assays as diagnostic tests for proliferative enteropathy in pigs: a review. J Vet Diagn Invest 22:487-494.

6. Pedersen KS, Stege H, Nielsen JP: 2011, Evaluation of a microwave method for dry matter determination in faecal samples from weaned pigs with or without clinical diarrhoea. Prev Vet Med 100:163-170.

7. Ståhl M, Kokotovic B, Hjulsager CK, et al.: 2011, The use of quantitative PCR for identification and quantification of Brachyspira pilosicoli, Lawsonia intracellularis and Escherichia coli fimbrial types F4 and F18 in pig feces. Vet Microbiol 151:307-314.

8. Yang S, Lin S, Khalil A, et al.: 2005, Quantitative PCR assay using sputum samples for rapid diagnosis of pneumococcal pneumonia in adult emergency department patients. J Clin Microbiol 43:3221-3226. 